\title{
Erratum to: Peroxisome proliferator-activated receptor gamma activates fas ligand gene promoter inducing apoptosis in human breast cancer cells
}

\author{
Daniela Bonofiglio $^{1} \cdot$ Sabrina Gabriele $^{1} \cdot$ Saveria Aquila $^{1,2} \cdot$ Hongyan $\mathbf{Q i}^{1}$ \\ Maria Belmonte $^{1} \cdot$ Stefania Catalano $^{1,2} \cdot$ Sebastiano Andò ${ }^{2,3,4}$
}

Published online: 18 August 2017

(C) Springer Science+Business Media, LLC 2017

\section{Erratum to: Breast Cancer Res Treat (2009) 113:423-434 \\ DOI 10.1007/s10549-008-9944-1}

and the new Fig. 5a-c were provided in this erratum. The authors apologize for the inconvenience caused.

Unfortunately, the authors could not find the blots of the original figures of $5 \mathrm{a}-\mathrm{c}$. As suggested by the Editor, the authors have repeated the experiments relative to Fig. $5 \mathrm{a}-\mathrm{c}$

The online version of the original article can be found under doi:10.1007/s10549-008-9944-1.

Sebastiano Andò

sebastiano.ando@unical.it

1 Department of Pharmaco-Biology, University of Calabria, Arcavacata di Rende, Cosenza 87036, Italy

2 Centro Sanitario, University of Calabria, Arcavacata di Rende, Cosenza 87036, Italy

3 Faculty of Pharmacy, University of Calabria, Arcavacata di Rende, Cosenza 87036, Italy

4 Department of Cellular Biology, University of Calabria, Arcavacata di Rende, Cosenza 87036, Italy 
Fig. 5 BRL induces the extrinsic apoptotic pathway in MCF7 cells. PPAR $\gamma($ a) and FasL (b) protein expression (evaluated by WB) in MCF7 cells transfected with a 25-nucleotide of RNA interference (RNAi) targeted human PPAR $\gamma$ or FasL mRNA sequence respectively, or with control RNAi as reported in Materials and Methods or not transfected and treated for $48 \mathrm{~h}$ as indicated. $\beta$-actin was used as loading control. c MCF7 cells were treated for $48 \mathrm{~h}$ as indicated, or transfected with PPAR $\gamma$, FasL or control RNAis. Positions of procaspase 8 (P) and its active cleavage product (S) are indicated by arrowheads on the right. One of three similar experiments is presented. $\beta$-actin was used as loading control on the same stripped blot. d DNA laddering was performed in MCF7 cells treated for 72-h as indicated, or transfected with PPAR $\gamma$ or control RNAis
A

PPAR $\gamma$
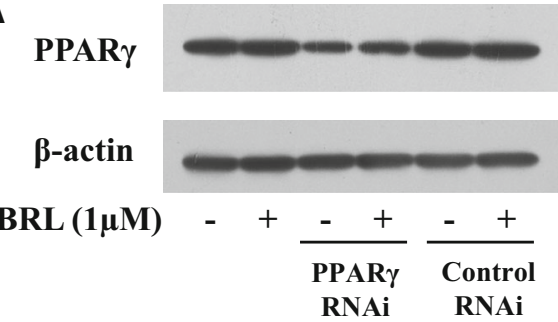

B

FasL

$\beta$-actin

BRL $(1 \mu M)$

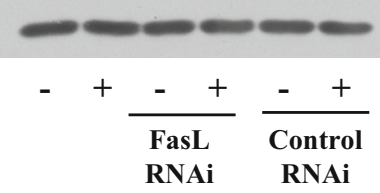

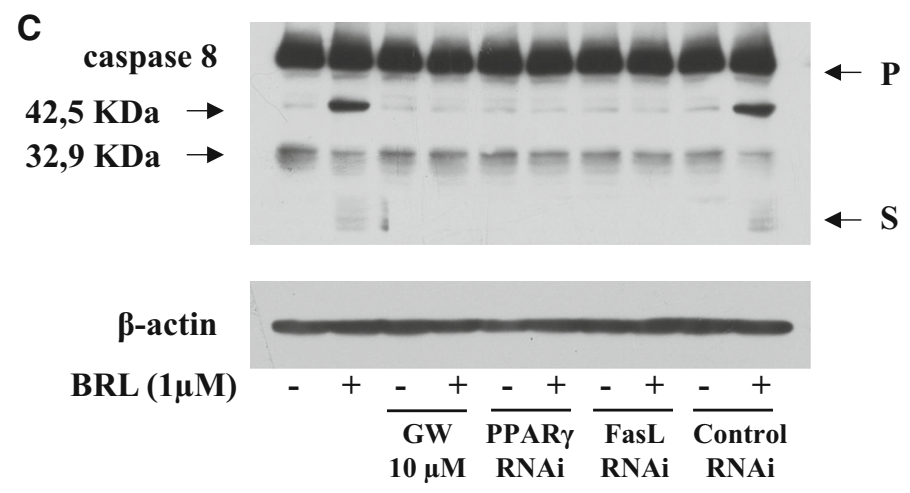

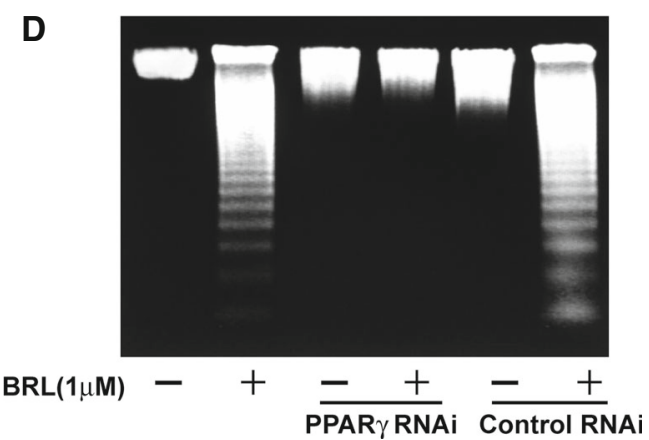

